\title{
Original
}

\section{High Resolution and High Precision Analysis of Barbiturates and a Metabolite in Human Body Fluids Using a Monolithic Spin Tip and UPLC-Q-ToF-MS}

\author{
Yukiko Shouji ${ }^{1}$, Chika Hasegawa ${ }^{* 1,2)}$, Xiao-Pen LeE*1), \\ Masaya FujISHIRO $^{1)}$, Takaaki MATSUYAMA ${ }^{1)}$, Miho YAMAdA ${ }^{1)}$, \\ Ayako KurIKI ${ }^{3)}$, Yuka KaTO ${ }^{1)}$, Noriko NeMOto ${ }^{1)}$, \\ Takeshi Kumazawa ${ }^{1,4)}$, Shinichi Suzuki ${ }^{1,5)}$ and Keizo Sato ${ }^{1)}$
}

\begin{abstract}
A high-throughput method was developed to analyze five barbiturates (phenobarbital, cyclobarbital, amobarbital, secobarbital, and thiopental) and a metabolite in human body samples using a new Monolithic $\mathrm{C}_{18}$ gel-packed Spin Tip and ultra-performance liquid chromatography (UPLC)-quadrupole-time-of-flight (Q-ToF) mass spectrometry $(\mathrm{MS})$. Plasma $(20 \mu \mathrm{l})$ or urine $(100 \mu \mathrm{l})$ samples spiked with the five barbiturates and 5-(4-methylphenyl)-5-phenylhydantoin (internal standard, IS) were mixed with distilled water. The mixture was extracted using the Monolithic $\mathrm{C}_{18}$ Spin Tip, and the analytes retained on the $\mathrm{C}_{18}$ phase were then eluted with methanol. The eluate was injected directly into an analytical column (Waters Acquity $\mathrm{BEH} \mathrm{C}_{18}, 50 \mathrm{~mm} \times 2.1 \mathrm{~mm}$ i.d., particle size $1.7 \mu \mathrm{m}$ ), and quantified by Q-ToF-MS with negative-ion electrospray ionization (ESI). Good separation and clear peak shapes of the five drugs were achieved within an analysis time of $6 \mathrm{~min}$, including the extraction time. All drugs spiked in the plasma showed recoveries of $86-98 \%$. The regression equations for the five drugs showed excellent linearities in the range of $5-500 \mathrm{ng} / 20 \mu \mathrm{l}$ of plasma, with limits of detection and i-Fit of $1 \mathrm{ng} / 20 \mu \mathrm{l}$. The method was also successfully applied to determine the level of amobarbital and its metabolite in human plasma and urine, respectively, after oral administration to a volunteer. This new method could be applied widely in the clinical and forensic fields for the quantitative determination of drugs and metabolites.
\end{abstract}

Key words : barbiturate drugs, Monolithic $\mathrm{C}_{18}$ Spin Tip, UPLC-Q-ToF-MS

\section{Introduction}

Barbiturates are a class of drugs derived from barbituric acid that act as sedative-hypnotics to the central nervous system ${ }^{1,2)}$. These drugs are frequently encountered in emergency toxicology

\footnotetext{
1) Department of Legal Medicine, Showa University School of Medicine, 1-5-8 Hatanodai, Shinagawa-ku, Tokyo 1428555, Japan.

2) Department of Legal Medicine, Toho University School of Medicine.

3) Stroke Center, Division of Neurology, Showa University Koto Toyosu Hospital.

4) Seirei Christopher University School of Nursing.

5) Identification Center, National Research Institute of Police Science.

* To whom corresponding should be addressed.
} 


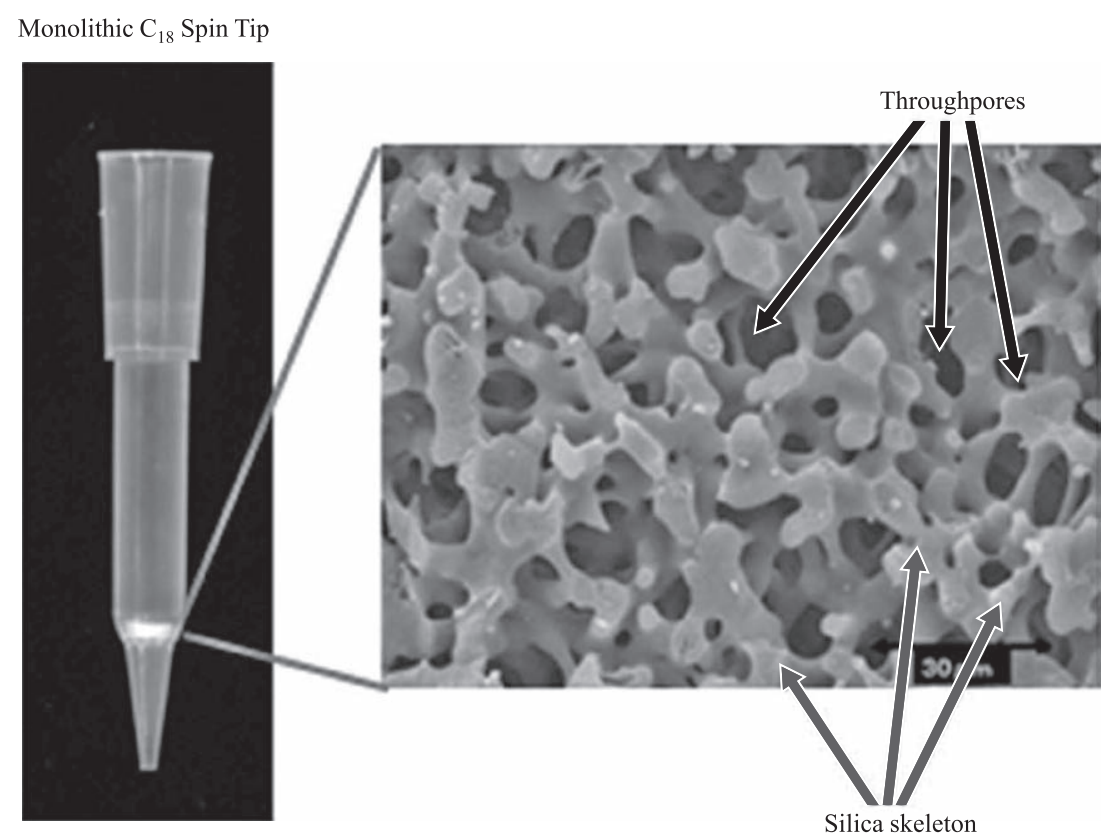

Fig. 1. Appearance of a Monolithic $\mathrm{C}_{18}$ gel-packed Spin Tip and electron micrograph of the monolithic silica gel.

screening, drug abuse testing, and forensic medical examinations ${ }^{3,4)}$. Accurate methods for detecting and measuring barbiturates in human samples are therefore required both for the diagnosis and effective treatment of intoxication and for forensic purposes.

Several methods have been reported for determining the levels of barbiturates in various matrices using gas chromatography $(\mathrm{GC})^{5)}$, GC-mass spectrometry (MS ${ }^{6,7)}$, high-performance liquid chromatography (HPLC) ${ }^{8,9)}$, and HPLC-MS or HPLC-tandem MS (MS-MS) ${ }^{10,11)}$. Due to the range of sample impurities present in human body fluids, most of these analytical techniques employ extraction steps such as liquid-liquid extraction (LLE) ${ }^{6,8-10)}$, solid-phase extraction $(\mathrm{SPE})^{11)}$, or solid-phase microextraction ${ }^{7)}$. Although LLE and SPE can successfully extract drugs from biological fluids, these procedures are generally performed in the off-line mode and are often labor-intensive and time-consuming.

In this study, we discuss new and unique monolithic silica SPE techniques for sample preparation using spin tips, which offer more simple and faster extractions than the conventional SPE cartridges. Figure 1 depicts the commercially available Monolithic $\mathrm{C}_{18}$ gel-packed Spin Tip. The small bed volume and sorbent mass within such tips allow for the use of reduced solvent and elution volumes, reduced extraction times, and higher throughput.

HPLC-MS/MS based mainly on triple quadrupole instruments is currently the most widely applied system for analyzing biological samples ${ }^{10-17)}$. When operating in the multiple reactionmonitoring (MRM) mode, HPLC-MS/MS systems obtain reliable quantitative information; however, the qualitative information needed to support the structural elucidation of analytes is poor. Recently, HPLC/quadrupole time-of-flight (Q-TOF)-MS has been used for the unequivocal confirmation of compounds from biological and environment samples by accurate mass measurement 
of protonated and deprotonated molecules ${ }^{18-21)}$. Accurate mass measurements of MS/MS product ions have also become particularly important in the structural elucidation of unknowns. Indeed, Q-ToF-MS is unique in its ability to give accurate mass measurements of product ions, assuring the correct identification of both target compounds and unknowns.

In the present study, we established a reproducible and practical procedure for analyzing five barbiturates (phenobarbital, cyclobarbital, amobarbital, secobarbital, thiopental) in human plasma samples and a metabolite of amobarbital in human urine using Monolithic $\mathrm{C}_{18}$ Spin Tip extraction and UPLC-Q-ToF-MS analysis. This is the first report on using a Monolithic $\mathrm{C}_{18}$ Spin Tip for extracting barbituric acid drugs from human body fluids.

\section{Materials and methods}

\section{Materials}

Amobarbital was provided by Nippon Shinyaku Co., Ltd. (Kyoto, Japan) and the cyclobarbital was purchased from Tokyo Kasei Industry Co., Ltd. (Tokyo, Japan). Phenobarbital, secobarbital, thiopental, and 5-(4-methylphenyl)-5-phenylhydantoin (internal standard, IS) were purchased from Sigma-Aldrich (St. Louis, MO), with the HPLC-MS-grade acetonitrile obtained from Wako Pure Chemical Industries Ltd. (Osaka, Japan). Other common chemicals used were of the highest

purity commercially available. Ultra-pure water from the Milli-Q ultra-pure system (Komatsu Electronics Co., Ltd., Ishikawa, Japan) was used in all experiments. Monolithic $\mathrm{C}_{18}$ Spin Tips $\left(\mathrm{C}_{18}\right.$-bonded monolithic silica gel with a diameter of $2.8 \mathrm{~mm}$, thickness of $1 \mathrm{~mm}$, weight of $2.5 \mathrm{mg}$, mesopore size of $10 \mathrm{~nm}$, through pore size of $5 \mu \mathrm{m}$, and surface area of $350 \mathrm{~m}^{2} / \mathrm{g}$ ) were purchased from GL Sciences.

\section{Preparation of plasma samples}

Drug-free whole blood samples were obtained intravenously in the presence of heparin sodium as an anticoagulant from healthy volunteers recruited from laboratory personnel. To prepare drug-free plasma samples, heparinized whole blood was centrifuged at $1,700 \times \mathrm{g}$ for $10 \mathrm{~min}$ at $4^{\circ} \mathrm{C}$, and the plasma was decanted into a clean centrifuge tube. Samples were stored at $-80^{\circ} \mathrm{C}$ until use. Obtaining blood samples from healthy volunteers was approved by the Ethics Committees of Showa University School of Medicine (No. 1249).

\section{Preparation of standard solutions and quality control samples}

Individual stock standard solutions $(1 \mathrm{mg} / \mathrm{ml})$ of the five barbiturates and the IS were prepared separately by dissolving an accurately weighed quantity of each drug in methanol. The solutions were then stored at $4^{\circ} \mathrm{C}$. Working standard solutions of these drugs were prepared by appropriate dilution of the stock standard solutions using the HPLC mobile phase (10 mM ammonium acetate in 50\% acetonitrile). All working standard solutions were freshly prepared every week and stored at $4^{\circ} \mathrm{C}$. Calibration standards were prepared by mixing appropriate amounts of the working standard solutions and drug-free plasma to achieve seven different concentrations ranging from 5 to $500 \mathrm{ng} / 20 \mu \mathrm{l}(5,10,25,50,100,250$, and $500 \mathrm{ng} / 20 \mu \mathrm{l})$ for five 
barbiturates, and $100 \mathrm{ng} / 20 \mu \mathrm{l}$ for the IS. Quality control (QC) samples (10-500 ng/20 $\mu \mathrm{l}$ ) for all test drugs were also prepared using the same procedure.

\section{Extraction procedure using the Monolithic $C_{18}$ Spin Tip}

The five barbiturates and IS were extracted from human plasma and urine using a Monolithic $\mathrm{C}_{18}$ Spin Tip, conditioned with $100 \mu \mathrm{l}$ methanol and centrifugation at $1,000 \times g$ for $15 \mathrm{~s}$, followed by $100 \mu \mathrm{l}$ of ultra-pure water at $1,000 \times g$ for $15 \mathrm{~s}$. For new tips, this procedure was repeated to reduce the background noise. To $20 \mu \mathrm{l}$ of a human plasma sample containing $10 \mu \mathrm{l}$ of drug mixture (five barbiturates and IS), $10 \mu \mathrm{l}$ of $1 \mathrm{~N} \mathrm{HCl}$ solution and $160 \mu \mathrm{l}$ of ultra-pure water were added. For human urine samples of $100 \mu \mathrm{l}$ of urine containing $10 \mu \mathrm{l}$ of drug mixture (five barbiturates and IS), $10 \mu \mathrm{l}$ of $1 \mathrm{~N} \mathrm{HCl}$ solution and $80 \mu \mathrm{l}$ of ultra-pure water were added. The sample solution was applied to the conditioned Monolithic $\mathrm{C}_{18}$ Spin Tip and centrifuged at $1,000 \times g$ for $15 \mathrm{~s}$. The spin tip was then washed with $100 \mu \mathrm{l}$ of ultra-pure water at $1,000 \times g$ for $15 \mathrm{~s}$, and the analytes were eluted from the spin tip with $50 \mu \mathrm{l}$ of methanol at $1,000 \times g$ for $10 \mathrm{~s}$. A $5-\mu \mathrm{l}$ aliquot of the eluate was directly analyzed by UPLC-Q-ToF-MS.

\section{UPLC-Q-ToF-MS conditions}

A UPLC-Q-ToF-MS system consisting of an Acquity UPLC liquid chromatograph (Waters, Milford, MA, USA) and a Xevo G2 Q-TOF mass spectrometer (Waters) was used for all measurements.

The Waters Acquity UPLC system was equipped with a binary solvent manager, sample manager, and column oven, and chromatographic separation of the five barbiturates and IS was achieved on a Waters Acquity UPLC BEH $\mathrm{C}_{18}$ column $(50 \mathrm{~mm} \times 2.1 \mathrm{~mm}$., particle size $17-\mu \mathrm{m}$ ) with a linear gradient elution system composed of $10 \mathrm{mM}$ ammonium acetate ( $\mathrm{pH}$ 6.8) and methanol at a flow rate of $0.4 \mathrm{ml} / \mathrm{min}$. Solvent A was ultra-pure water containing $10 \mathrm{mM}$ ammonium acetate, and solvent $\mathrm{B}$ was methanol. Gradient runs were programmed to change from $90 \%$ solvent $\mathrm{A} / 10 \%$ solvent $\mathrm{B}$ to $50 \%$ solvent $\mathrm{A} / 50 \%$ solvent $\mathrm{B}$ within $2.5 \mathrm{~min}$, and then to $1 \%$ solvent $\mathrm{A} / 99 \%$ solvent $\mathrm{B}$ within $2.5 \mathrm{~min}$. The column was subsequently maintained with $1 \%$ solvent $\mathrm{A} / 99 \%$ solvent $\mathrm{B}$ for $1.0 \mathrm{~min}$, and then re-equilibrated with $90 \%$ solvent $\mathrm{A} / 10 \%$ solvent $\mathrm{B}$ for $2.0 \mathrm{~min}$ before the next injection. The total chromatographic run time was $8 \mathrm{~min}$.

For confirmation, mass spectrometric measurements were performed using a Xevo G2 Q-TOF mass spectrometer. The analyses were carried out using the ESI setting in the negative mode $\left(\mathrm{ESI}^{-}\right)$. The mass spectrometer was operated in negative ionization mode, with a capillary voltage of $2.8 \mathrm{kV}$ and a cone voltage of $30 \mathrm{~V}$. The source and desolvation temperatures were $150^{\circ} \mathrm{C}$ and $500^{\circ} \mathrm{C}$, respectively. The desolvation gas flow was $1,0001 / \mathrm{hr}$ and the cone gas flow $50 \mathrm{l} / \mathrm{hr}$ (both $\mathrm{N}_{2}$ ). The mass range considered was 100-1,000 Da. Data were collected in centroid mode, with the sensitivity analyzer mode selected. The accuracy and reproducibility of all analyses were guaranteed by the use of a LockSpray. Leucine-enkephalin was used as the lock mass at a concentration of $1 \mathrm{ng} / \mathrm{ml}$ in $50 \%$ of ultra-pure water-acetonitrile with $0.1 \%$ formic acid and a flow rate of $5 \mu \mathrm{l} / \mathrm{min}$. MassLynx version 4.1 (Waters) was used to analyze the samples with the 
following parameter settings: analysis time of 0-6 min; spectrum above the relative intensity of $2 \%$; and, a maximum tolerance of mass error set as $5 \mathrm{ppm}$. The prediction rules of elemental composition (EC) were defined as follows: atom numbers of carbon, hydrogen, oxygen, nitrogen, and sulfur were set to ranges of 0-100, 0-200, 0-20, 0-20, and 0-6, respectively. The molecular formula assignments were obtained with the MassLynx i-Fit algorithm. For barbiturates and IS, the search was restricted to molecules containing CHONS only and the best fit was obtained on both mass accuracy and isotope intensity pattern (i-Fit). Blank human plasma or urine samples were used as controls for comparison with the analytic samples, and all were processed under the same conditions.

\section{Methods validation}

The method was validated for linearity, selectivity, precision, accuracy, and recovery according to the US Food and Drug Administration guidelines for bioanalytical method validation ${ }^{22)}$. Regression equations of the barbiturates were obtained by plotting the peak-area ratio of analytes/IS ( $y$-axis) against the analyte concentration ( $x$-axis). The slope and $y$-intercept of the regression line were estimated in duplicate for each of ten different calibrations and on six consecutive days. The acceptance criterion for the correlation coefficient was $>0.998$. The limit of detection (LOD) was defined as the lowest concentration of analyte spiked in plasma that could be detected with a signal-to-noise ratio of at least 3. The lower limit of quantification (LLOQ) was defined as the lowest concentration on the calibration curve that could be measured with a signal-to-noise ratio of at least 10 .

The selectivity of the method was estimated by analyzing blank human plasma matrix samples. The responses of the interfering substances or background noises at the retention time of barbiturates and IS were acceptable if less than $5 \%$ of the mean response of the LLOQ. Intra-day precision and accuracy were carried out by analyzing QC samples spiked with the five barbiturates at three different concentrations $(10,100$, and $500 \mathrm{ng} / 20 \mu \mathrm{l})$ in six replicate samples on the same day. The concentration of analytes in the QC samples was calculated using the calibration curves. The precision was determined by calculating the coefficient of variation $(\mathrm{CV})$, while the accuracy was expressed as a percentage of the mean of measured concentration against the nominal concentration. The evaluations of precision were based on previously published criteria ${ }^{22)}$. The acceptance criterion for precision (percentage CV) was $\leq 15 \%$. Recovery was calculated by comparing the chromatographic peak areas of the analyte in QC samples with those obtained by direct injection of analyte standards dissolved in $10 \mathrm{mM}$ ammonium acetate, and determined at different concentration levels $(10,100$, and $500 \mathrm{ng} / 20 \mu \mathrm{l})$.

\section{Administration of amobarbital to a healthy volunteer}

The present method was applied to real samples of human plasma to confirm its utility. A therapeutic dose of amobarbital $(300 \mathrm{mg}$ ) was administered orally to a 40-year-old male volunteer (body weight, $73 \mathrm{~kg}$ ), after obtaining his informed consent. Whole blood samples were collected pre-dose $(0 \mathrm{~h})$ and $1.5 \mathrm{~h}$ after drug administration, and transferred to centrifuge tubes 
Table 1. Mass spectral data for five barbiturate drugs and an internal standard (IS) extracted from human plasma

\begin{tabular}{lcccccc}
\hline $\begin{array}{l}\text { Compound } \\
{[\mathrm{M}-\mathrm{H}]^{-}}\end{array}$ & $\begin{array}{c}\text { Molecular } \\
\text { formula }\end{array}$ & $\begin{array}{c}\text { Theoretica } \\
m / z\end{array}$ & $\begin{array}{c}\text { Experimental } \\
m / z\end{array}$ & \multicolumn{2}{c}{ Error } & $\begin{array}{c}\text { i-Fit } \\
(\mathrm{Norm})\end{array}$ \\
\cline { 5 - 7 } Phenobarbital & $\mathrm{C}_{12} \mathrm{H}_{11} \mathrm{~N}_{2} \mathrm{O}_{3}$ & 231.0770 & 231.0765 & -0.5 & -2.2 & 0.020 \\
Cyclobarbital & $\mathrm{C}_{12} \mathrm{H}_{15} \mathrm{~N}_{2} \mathrm{O}_{3}$ & 235.1083 & 235.1076 & -0.7 & -3.0 & 0.015 \\
Amobarbital & $\mathrm{C}_{11} \mathrm{H}_{17} \mathrm{~N}_{2} \mathrm{O}_{3}$ & 225.1239 & 225.1231 & -0.8 & -3.6 & 0.093 \\
Secobarbital & $\mathrm{C}_{12} \mathrm{H}_{17} \mathrm{~N}_{2} \mathrm{O}_{3}$ & 237.1239 & 237.1232 & -0.7 & -3.0 & 0.010 \\
$\begin{array}{l}\text { Thiopental } \\
\text { 5-(4-methylpheny)-5 }\end{array}$ & $\mathrm{C}_{11} \mathrm{H}_{17} \mathrm{~N}_{2} \mathrm{O}_{2} \mathrm{~S}$ & 241.1011 & 241.1006 & -0.5 & -2.1 & 0.461 \\
-phenylhydantoin (IS) & $\mathrm{C}_{16} \mathrm{H}_{13} \mathrm{~N}_{2} \mathrm{O}_{2}$ & 265.0977 & 265.0970 & -0.7 & -1.6 & 0.017 \\
\hline
\end{tabular}

Identification analyses were obtained using Mass Lynx 4.1 software. Drug-free plasma samples (20 $\mu$ l) were spiked with $50 \mathrm{ng}$ each of drugs and $100 \mathrm{ng}$ of IS. The i-Fit (Norm) is the correctness of isotope patterns for elemental composition. Lower i-Fit normalized values indicate higher precision of the elemental composition.

containing heparin sodium. The heparinized blood samples were centrifuged at $1,700 \times g$ for $10 \mathrm{~min}$ at $4^{\circ} \mathrm{C}$, and the resulting plasma samples were stored at $-80^{\circ} \mathrm{C}$ until analysis. This study was approved by the Ethics Committee of Showa University School of Medicine (No 860).

\section{Results}

The extracted ion chromatogram (XIC) chromatograms and mass spectral data for the five barbiturates and IS obtained by UPLC-Q-ToF-MS using an ESI are shown in Figure 2 and Table 1. Phenobarbital, cyclobarbital, amobarbital, secobarbital, thiopental, and the IS detected in negative-ion mode gave the deprotonated molecule $[\mathrm{M}-\mathrm{H}]^{-}$at $\mathrm{m} / \mathrm{z}$ 231.0765, 235.1076, 225.1231, 237.1232, 241.1006, and 265.0970, respectively, in the full-scan mode. These deprotonated molecules were identified as $\mathrm{C}_{12} \mathrm{H}_{11} \mathrm{~N}_{2} \mathrm{O}_{3}$ (-2.2 ppm mass error, $0.020 \mathrm{i}$-Fit) for phenobarbital, $\mathrm{C}_{12} \mathrm{H}_{15} \mathrm{~N}_{2} \mathrm{O}_{3}$ (-3.0 ppm mass error, $0.015 \mathrm{i}$-Fit) for cyclobarbital, $\mathrm{C}_{11} \mathrm{H}_{17} \mathrm{~N}_{2} \mathrm{O}_{3}$ (-3.6 ppm mass error, 0.093 i-Fit) for amobarbital, $\mathrm{C}_{12} \mathrm{H}_{17} \mathrm{~N}_{2} \mathrm{O}_{3}$ (-3.0 ppm mass error, 0.010 i-Fit) for secobarbital, $\mathrm{C}_{11} \mathrm{H}_{17} \mathrm{~N}_{2} \mathrm{O}_{2} \mathrm{~S}$ (-2.1 ppm mass error, $0.461 \mathrm{i}$-Fit) for thiopental, and $\mathrm{C}_{16} \mathrm{H}_{13} \mathrm{~N}_{2} \mathrm{O}_{2}$ (-1.6 ppm mass error, $0.017 \mathrm{i}$-Fit) for IS.

The regression equations of the five barbiturates showed good linearity at $5-500 \mathrm{ng} / 20 \mu \mathrm{l}$ with correlation coefficients of at least 0.9984 (Table 2). The LOD and LLOQ of the barbiturates in plasma under optimal conditions were $1 \mathrm{ng} / 20 \mu \mathrm{l}$ and $5 \mathrm{ng} / 20 \mu \mathrm{l}$, respectively (Table 2). Intraday precisions and accuracies were evaluated by assessing QC samples prepared from human plasma (Table 3). The intra-day CVs were no greater than $7.8 \%$, and the accuracies ranged from $86.3 \%$ to $97.9 \%$ for all concentrations. The recoveries of the five barbiturates from human plasma samples determined at three different concentrations ranged within 89.6-97.1\% (Table 4).

In addition to analysis of spiked human plasma, the present method was applied to human plasma and urine samples collected following oral administration of amobarbital (300 mg) to a male volunteer. The IS concentration was measured at $100 \mathrm{ng} / 20 \mu \mathrm{l}$ for plasma and $100 \mathrm{ng} / 100 \mu \mathrm{l}$ for urine. Figure 3 shows UPLC-Q-ToF-MS XICs chromatograms and typical EC spectra for 


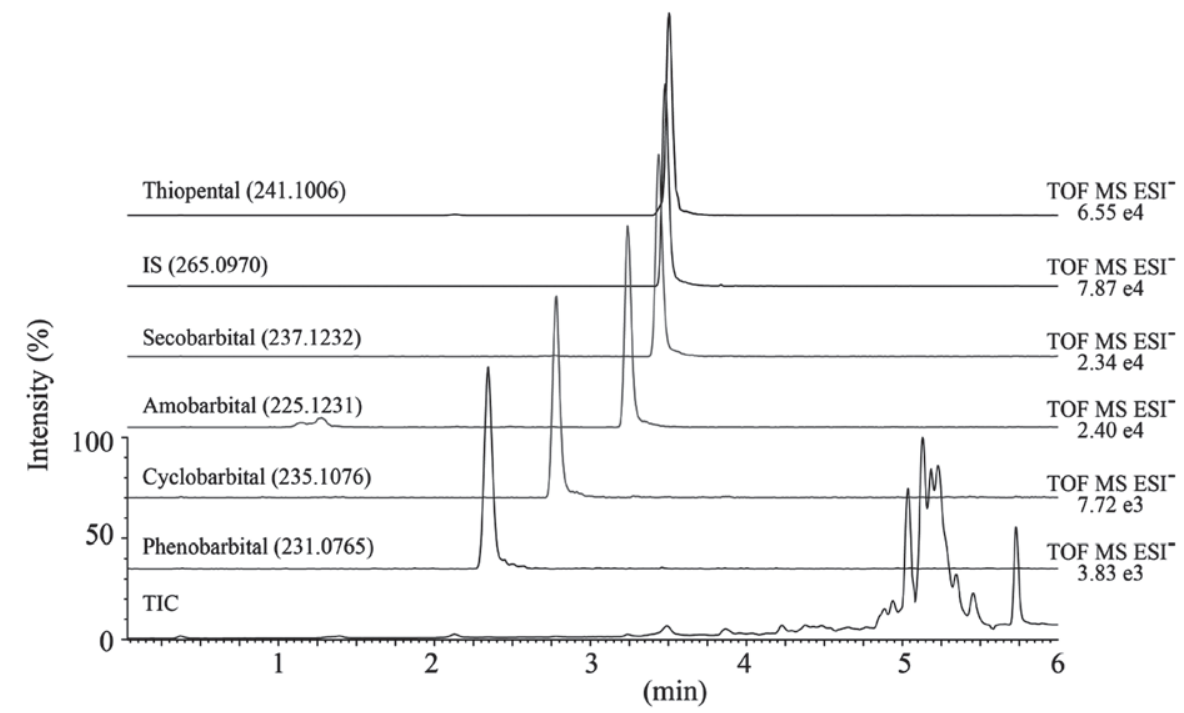

Fig. 2. TIC and XIC chromatograms of UPLC-Q-TOF-MS for barbiturate drugs from human plasma in negative ESI mode. The mixture of drugs (50 ng each) and 5-(4-methylphenyl)-5-phenylhydantoin used as IS (100 ng) were spiked into $20 \mu \mathrm{l}$ of plasma. The MS spectra of XIC chromatograms are consistent with those reported in Table 1.

Table 2. Regression equations, LODs, LLOQs, Error, and i-Fit (Norm) for barbiturate drugs extracted from human plasma

\begin{tabular}{|c|c|c|c|c|c|c|c|c|}
\hline \multirow{2}{*}{ Compound } & \multirow{2}{*}{ Equation $^{\mathrm{a}}$} & \multirow{2}{*}{$\begin{array}{l}\text { Correlation } \\
\text { coefficient }(r)\end{array}$} & \multirow{2}{*}{$\begin{array}{c}\text { Concentration } \\
\text { range } \\
(\mathrm{ng} / 20 \mu \mathrm{l})\end{array}$} & \multirow{2}{*}{$\begin{array}{c}\text { LOD } \\
(\mathrm{ng} / 20 \mu \mathrm{l})\end{array}$} & \multirow{2}{*}{$\begin{array}{c}\text { LLOQ } \\
(\mathrm{ng} / 20 \mu \mathrm{l})\end{array}$} & \multicolumn{2}{|c|}{ Error } & \multirow{2}{*}{$\begin{array}{c}\text { i-Fit } \\
\text { (Norm) }\end{array}$} \\
\hline & & & & & & $\mathrm{mDa}$ & ppm & \\
\hline Phenobarbital & $y=0.3441 x-0.4936$ & 0.9989 & $5-250$ & 1 & 5 & -0.8 & -3.5 & 0.058 \\
\hline Cyclobarbital & $y=0.5762 x-0.0885$ & 0.9990 & $5-250$ & 1 & 5 & -0.5 & -2.1 & 0.068 \\
\hline Amobarbital & $y=1.7107 x-2.1699$ & 0.9986 & $5-500$ & 1 & 5 & -0.9 & -4.0 & 0.183 \\
\hline Secobarbital & $y=1.7112 x-2.3124$ & 0.9984 & $5-500$ & 1 & 5 & -0.8 & -3.4 & 0.134 \\
\hline Thiopental & $y=4.0314 x-5.1121$ & 0.9987 & $5-500$ & 1 & 5 & -1.0 & -4.1 & 0.000 \\
\hline
\end{tabular}

${ }^{\mathrm{a}}$ The data were subjected to linear regression analysis of peak area ratios $(y)$ of a compound to IS (100 ng) against the spiking concentrations $(x)$. Seven plots (each point represents the mean of duplicate determinations) with different concentrations for each drug were used. The error and i-Fit were obtained under LLOQ concentrations.

human plasma $1.5 \mathrm{~h}$ after oral administration. The drug concentration in plasma calculated by internal calibration was $44.1 \mathrm{ng} / 20 \mu \mathrm{l}$ at $1.5 \mathrm{~h}$ after the administration of amobarbital. The amobarbital and its hydroxide metabolite were identified using the present method from human urine $8 \mathrm{~h}$ after oral administration (Fig. 4). The deprotonated molecule was assigned as $\mathrm{C}_{11} \mathrm{H}_{17} \mathrm{~N}_{2} \mathrm{O}_{4}$ (-2.5 ppm mass error, 0.354 i-Fit) for 3-hydroxyamobarbital (Fig. 4).

\section{Discussion}

Optimization of extraction conditions for the Monolithic $C_{18}$ Spin Tip

The entire Monolithic $\mathrm{C}_{18}$ Spin Tips extraction process including conditioning, sample loading, 
Table 3. Precision and accuracy of intra-day analyses for five barbiturate drugs in QC samples

\begin{tabular}{|c|c|c|c|c|}
\hline Compound & $\begin{array}{c}\text { Concentration } \\
\text { added }(\mathrm{ng} / 20 \mu \mathrm{l})\end{array}$ & $\begin{array}{c}\text { Concentration } \\
\text { found }(\mathrm{ng} / 20 \mu \mathrm{l})^{\mathrm{a}}\end{array}$ & $\begin{array}{l}\text { Precision } \\
(\mathrm{CV}, \%)\end{array}$ & $\begin{array}{c}\text { Accuracy } \\
(\%)\end{array}$ \\
\hline \multirow[t]{3}{*}{ Phenobarbital } & 10 & $8.63 \pm 0.41$ & 4.8 & 86.3 \\
\hline & 100 & $88.4 \pm 4.69$ & 5.3 & 88.4 \\
\hline & 500 & $458 \pm 26.1$ & 5.7 & 91.6 \\
\hline \multirow[t]{3}{*}{ Cyclobarbital } & 10 & $8.94 \pm 0.37$ & 4.1 & 89.4 \\
\hline & 100 & $88.3 \pm 5.33$ & 6.0 & 88.3 \\
\hline & 500 & $453 \pm 17.8$ & 3.9 & 90.5 \\
\hline \multirow[t]{3}{*}{ Amobarbital } & 10 & $9.27 \pm 0.35$ & 3.8 & 92.7 \\
\hline & 100 & $91.8 \pm 4.24$ & 4.6 & 91.8 \\
\hline & 500 & $458 \quad \pm 25.1$ & 5.5 & 91.6 \\
\hline \multirow[t]{3}{*}{ Secobarbital } & 10 & $9.31 \pm 0.54$ & 5.8 & 93.1 \\
\hline & 100 & $94.7 \pm 4.74$ & 5.0 & 94.7 \\
\hline & 500 & $468 \pm 21.8$ & 4.7 & 93.5 \\
\hline \multirow[t]{3}{*}{ Thiopental } & 10 & $9.53 \pm 0.74$ & 7.8 & 95.3 \\
\hline & 100 & $97.9 \pm 6.81$ & 7.0 & 97.9 \\
\hline & 500 & $472 \pm 33.6$ & 7.1 & 94.4 \\
\hline
\end{tabular}

$\mathrm{CV}$, coefficient of variation.

${ }^{a}$ Values represent means $\pm \mathrm{SD}$ of six experiments.

Table 4. Recovery rates for barbiturate drugs from human plasma

\begin{tabular}{lcc}
\hline Compound & $\begin{array}{c}\text { Concentration added } \\
(\mathrm{ng} / 20 \mu \mathrm{l})\end{array}$ & $\begin{array}{c}\text { Recovery } \\
(\%)\end{array}$ \\
\hline Phenobarbital & 10 & $89.6 \pm 3.3$ \\
& 100 & $91.7 \pm 6.1$ \\
& 500 & $92.1 \pm 5.7$ \\
Cyclobarbital & 10 & $91.6 \pm 5.1$ \\
& 100 & $90.1 \pm 5.9$ \\
& 500 & $91.5 \pm 7.3$ \\
Amobarbital & 10 & $93.7 \pm 6.6$ \\
& 100 & $95.4 \pm 6.1$ \\
Secobarbital & 500 & $94.1 \pm 5.7$ \\
& 10 & $93.0 \pm 7.3$ \\
& 100 & $92.9 \pm 6.9$ \\
Thiopental & 500 & $96.1 \pm 4.9$ \\
& 10 & $93.7 \pm 5.9$ \\
& 100 & $95.9 \pm 4.8$ \\
& 500 & $97.1 \pm 6.1$ \\
\hline
\end{tabular}

${ }^{\mathrm{a}}$ Values represent means $\pm \mathrm{SD}$ of six experiments. 


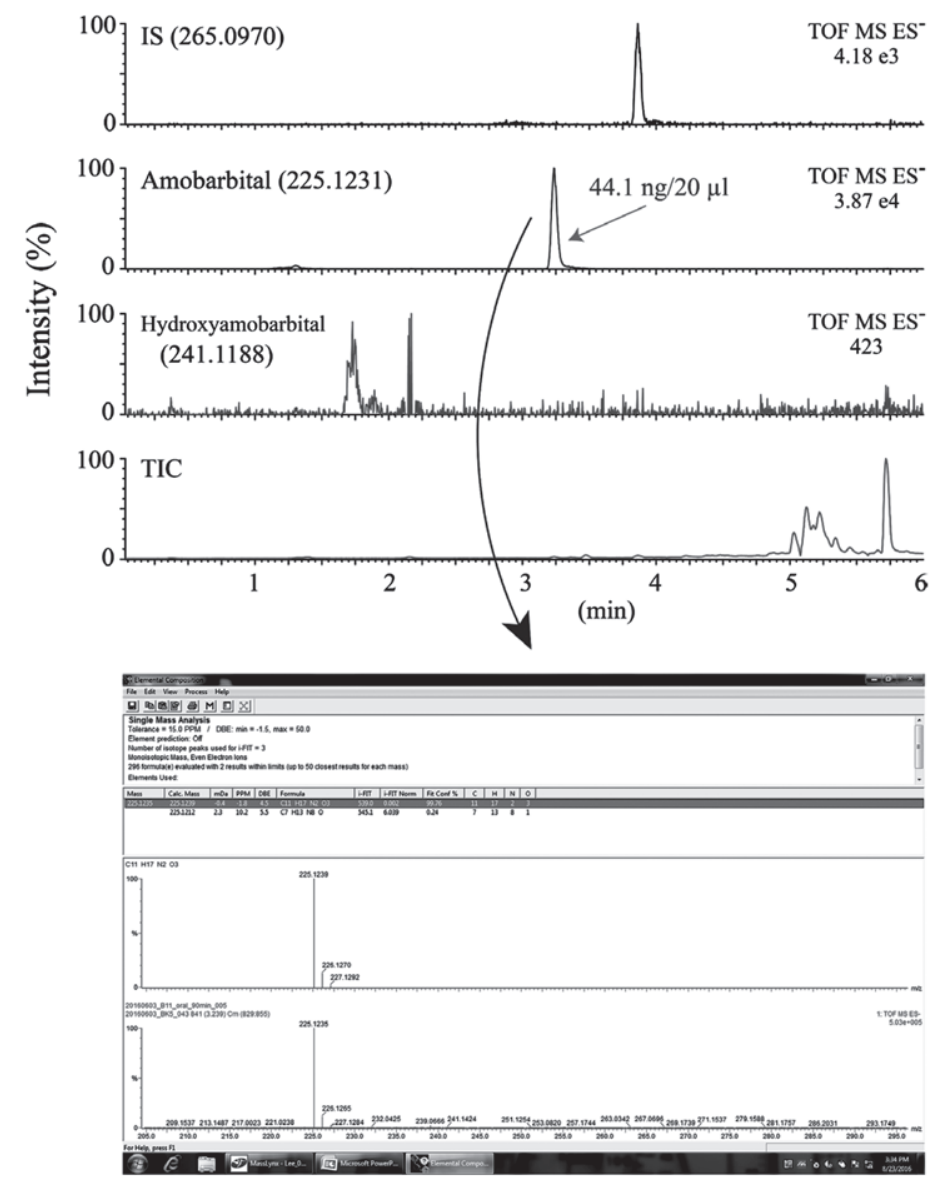

Fig. 3. UPLC-Q-Tof-MS XICs chromatograms and spectra of elemental composition from human plasma $1.5 \mathrm{~h}$ after oral administration of amobarbital $(300 \mathrm{mg})$. The amount of 5-(4-methylphenyl)-5-phenylhydantoin used as IS was $100 \mathrm{ng} / 20 \mu \mathrm{l}$ of plasma.

washing, and elution required approximately $2 \mathrm{~min}$. In contrast, the time required to manually perform conventional cartridge SPE exceeds $20 \mathrm{~min}^{23-26)}$. In addition, eluate from the Monolithic $\mathrm{C}_{18}$ Spin Tips was directly injected into the UPLC-Q-ToF-MS without evaporation and reconstitution steps, which is particularly important for rapid and simple analyses. Therefore, the use of Monolithic $\mathrm{C}_{18}$ Spin Tips is recommended for rapid extraction of barbiturates and its metabolites from human body fluids. The total solvent volume used for each step of the extraction process was $500 \mu \mathrm{l}$, which is lower than volumes required by conventional SPE cartridges (around 5.6$65 \mathrm{ml})^{23-26)}$. Furthermore, the required plasma or urine sample volume was reduced to 20 or $100 \mu \mathrm{l}$, respectively, which corresponds to 4.5-50 times less than volumes previously reported for barbiturates analysis in plasma and urine samples ${ }^{23-26)}$. Such small volumes of solvent and samples needed with the method used in this study represent a significant advance in sample preparation miniaturization and the overall procedure can be considered to be "green" because it requires little solvent and produces little waste. 


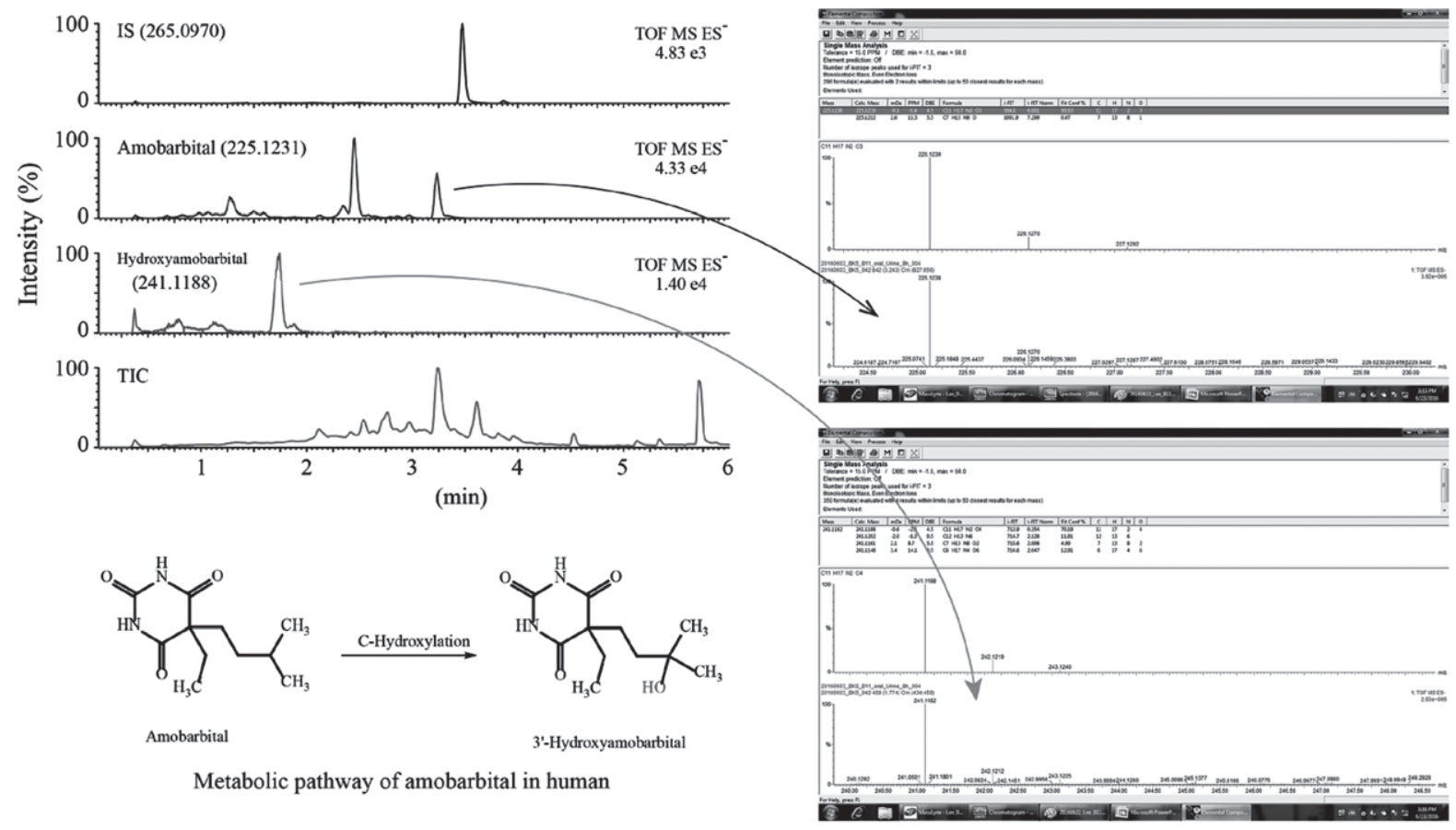

Fig. 4. UPLC-Q-Tof-MS XICs chromatograms and spectra of elemental composition from human urine $8 \mathrm{~h}$ after oral administration of amobarbital $(300 \mathrm{mg})$. The amount of 5-(4-methylphenyl)-5-phenylhydantoin used as IS was $100 \mathrm{ng} / 100 \mu \mathrm{l}$ of urine.

\section{Method performance}

Figure 2 shows TIC and XIC chromatograms obtained by UPLC-Q-ToF-MS for barbiturate drugs from human plasma containing the test compounds $(50 \mathrm{ng}$ per $20 \mu \mathrm{l})$. Distinct peaks appeared for each drug and the IS on the chromatograms within $4 \mathrm{~min}$. Blank chromatograms gave small impurity peaks and no interfering peaks appeared around the retention times of the test compounds (data not shown), and the spectra obtained showed accurate corresponding masses for the deprotonated molecular ions. The criteria of the potential candidate ions used for EC analysis included mass error ( $\mathrm{mDa}$ and $\mathrm{ppm}$ ), double bond equivalent (DBE, total number of rings and double bonds in a molecule), empirical formula, and i-Fit value (the likelihood that the isotopic pattern of the EC matches a cluster of peaks in the spectrum). The potential calculated masses, mass accuracy, DBE, i-Fit value, and ECs associated with the measured mass of the marker ion were generated and analyzed with the ChemSpider and SciFinder libraries. Thus, we obtained lower i-Fit values for barbiturates and IS (Table 1).

The present method also showed good linearity for the known components tested, with LOD and LLOQ for human plasma under optimal conditions corresponding to $1 \mathrm{ng} / 20 \mu \mathrm{l}$ and $5 \mathrm{ng} / 20 \mu \mathrm{l}$, respectively. Furthermore, lower i-Fit values were obtained under the LLOQ concentration (Table 2). With therapeutic levels in plasma or serum of barbiturates reported to be $10,000-40,000 \mathrm{ng} / \mathrm{ml}$ for phenobarbital ${ }^{27)}, 2,000-6,000 \mathrm{ng} / \mathrm{ml}$ for cyclobarbital $^{28)}, 2,500-4,000 \mathrm{ng} / \mathrm{ml}$ for amobarbital ${ }^{29)}, 1,000-2,200 \mathrm{ng} / \mathrm{ml}$ for secobarbital ${ }^{30)}$, and $25,000-50,000 \mathrm{ng} / \mathrm{ml}$ for thiopental ${ }^{31)}$, the present method is sensitive enough to analyze these drugs at therapeutic levels. 
The intra-day CVs at the three concentrations examined were below $7.8 \%$, and the accuracies ranged from $86.3 \%$ to $97.9 \%$ for all concentrations (Table 3), leading us to consider this variability acceptable for method validation based on the current criteria ${ }^{32,33)}$. Recovery rates of the five barbiturates from human plasma samples determined at three different concentrations ranged within 89.6-97.1\% (Table 4). The reduced recovery (below 100\%) is probably due to an overall loss of analyte during the sample preparation steps; however, the reduction was not problematic, because satisfactory quantification was achieved using the method described, as shown in Tables 2 and 3.

\section{Actual measurements of amobarbital in human plasma after oral administration}

In addition to the analysis of spiked human plasma, the present method was applied to human plasma samples collected following oral administration of amobarbital to a male volunteer (Fig. 3). The drug concentration in plasma calculated by internal calibration was $44.1 \mathrm{ng} / 20 \mu \mathrm{l}$ at $1.5 \mathrm{~h}$ after administration of amobarbital, and this concentration was within therapeutic levels for UPLC-Q-ToF-MS analysis ${ }^{29)}$.

\section{Conclusions}

We have established a detailed and novel procedure for the quantitative determination and identification of barbiturates and a metabolite in human body samples using a Monolithic $\mathrm{C}_{18}$ Spin Tip and UPLC-Q-ToF-MS analysis. Using the gel-packed spin tips represents an ideal sample preparation technique with simple extraction, and minimal sample and solvent requirements. The recovery rates of the five drugs from plasma were $86-98 \%$ and the LLOQ was $5 \mathrm{ng} / 20 \mu \mathrm{l}$. The intra-day CVs for all the drugs in plasma were less than $7.8 \%$. This method will be useful for high-throughput determination of barbiturates in clinical and toxicological analyses. We are currently developing this technique for the detection of other classes of drugs in human body fluid samples.

\section{Acknowledgments}

We thank Dr. Shota Miyazaki of GL Sciences, Tokyo, Japan, for kindly providing an electron micrograph of the monolithic silica gel. This study was supported in part by a Grant-in-Aid for Scientific Research from the Japan Society for the Promotion of Science (JSPS), KAKENHI grant(C) 26460886.

\section{Conflict of interest disclosure}

The authors declare no conflict of interest associated with this manuscript.

\section{References}

1) Charney DS, Mihic SJ, Harris RA. Hypnotics and sedatives. In Brunton LL, Lazo JS, Parker KL eds. Goodman \& Gilman's the pharmacological basis of therapeutics. 11th ed. New York: McGraw-Hill; 2006. pp 401-427.

2) Bland JM, Altman DG. Statistical methods for assessing agreement between two methods of clinical measurement. Lancet. 1986;1:307-310. 
3) Roberts DM, Buckley NA. Enhanced elimination in acute barbiturate poisoning: a systematic review. Clin Toxicol (Phila). 2011;49:2-12.

4) Kudo K, Ishida T, Hikiji W, et al. Pattern of poisoning in Japan: selection of drugs and poisons for systematic toxicological analysis. Forensic Toxicol. 2010;28:25-32.

5) Chow WML, Caddy B. Separation of underivatised barbiturates by capillary column gas chromatography: preparation of medium polar polymethylsiloxane columns to optimize selectivity. J Chromatogr A. 1985;318:255-268.

6) Zhao H, Wang L, Qiu Y, et al. Simultaneous determination of three residual barbiturates in pork using accelerated solvent extraction and gas chromatography-mass spectrometry. J Chromatogr B Analyt Technol Biomed Life Sci. 2006;840:139-145.

7) Iwai M, Hattori H, Arinobu $\mathrm{T}$, et al. Simultaneous determination of barbiturates in human biological fluids by direct immersion solid-phase microextraction and gas chromatography-mass spectrometry. J Chromatogr B Analyt Technol Biomed Life Sci. 2004;806:65-73.

8) Garcia-Borregon PF, Lores M, Cela R. Analysis of barbiturates by micro-high-performance liquid chromatography with post-column photochemical derivatization. J Chromatogr A. 2000;870:39-44.

9) Yoshida M, Akane A, Nishikawa M, et al. Extraction of thiamylal in serum using hydrophilic acetonitrile with subzero-temperature and salting-out methods. Anal Chem. 2004;76:4672-4675.

10) Ye F, Pan J, Hu G, et al. LC-APCI-MS Simultaneous determination of barbital, amobarbital, phenobarbital and secobarbital in human plasma. Chromatographia. 2010;72:743-746.

11) Feng J, Wang L, Dai I, et al. Simultaneous determination of multiple drugs of abuse and relevant metabolites in urine by LC-MS-MS. J Anal Toxicol. 2007;31:359-368.

12) Yamada M, Lee XP, Fujishiro M, et al. Highly sensitive determination of alendronate in human plasma and dialysate using metal-free HPLC-MS/MS. Legal Med (Tokyo). 2018;30:14-20.

13) Lee XP, Shouji Y, Kumazawa T, et al. Rapid and highly sensitive analysis of benzodiazepines and tandospirone in human plasma by automated on-line column-switching UFLC-MS/MS. Legal Med (Tokyo). 2017;24:36-55.

14) Hirosawa M, Sambe T, Uchida N, et al. Determination of nonsteroidal anti-inflammatory drugs in human tear and plasma samples using ultra-fast liquid chromatography-tandem mass spectrometry. Jpn J Ophthalmol. 2015;59:364-371.

15) Nemoto $\mathrm{T}$, Lee XP, Kumazawa $\mathrm{T}$, et al. High-throughput determination of nonsteroidal anti-inflammatory drugs in human plasma by HILIC-MS/MS. J Pharm Biomed Anal. 2014;88:71-80.

16) Arinobu T, Hattori H, Kumazawa $\mathrm{T}$, et al. High-throughput determination of theophylline and caffeine in human serum by conventional liquid chromatography-mass spectrometry. Forensic Toxicol. 2009;27:1-6.

17) Hoshina K, Horiyama S, Matsunaga $\mathrm{H}$, et al. Molecularly imprinted polymers for simultaneous determination of antiepileptics in river water samples by liquid chromatography-tandem mass spectrometry. $J$ Chromatogr $A$. 2009;1216:4957-4962.

18) Chen $\mathrm{ML}, \mathrm{Fu} \mathrm{XM}$, Liu JQ, et al. Highly sensitive and quantitative profiling of acidic phytohormones using derivatization approach coupled with nano-LC-ESI-Q-TOF-MS analysis. J Chromatogr B Analyt Technol Biomed Life Sci. 2012;905:67-74.

19) Moosmann B, Huppertz LM, Hutter M, et al. Detection and identification of the designer benzodiazepine flubromazepam and preliminary data on its metabolism and pharmacokinetics. J Mass Spectrom. 2013;48:1150-1159.

20) Zhao YY, Lin RC. UPLC-MS(E) application in disease biomarker discovery: the discoveries in proteomics to metabolomics. Chem Biol Interact. 2014;215:7-16.

21) Pizzatti L, Panis C, Lemos G, et al. Label-free MS(E) proteomic analysis of chronic myeloid leukemia bone marrow plasma: disclosing new insights from therapy resistance. Proteomics. 2012;12:2618-2631.

22) U.S. Department of Health and Human Services, Food and Drug Administration, Center for Drug Evaluation and Research, et al. Guidance for industry: bioanalytical method validation. 2013. (accessed 2017 Dec 24) Available from: http://www.fda.gov/Drugs/GuidanceComplianceRegulatoryInformation/Guidances/UCM368107 
23) Lee XP, Kumazawa T, Sato K. Rapid extraction and capillary gas chromatography for diazine herbicides in human body fluids. Forensic Sci Int. 1995;72:199-207.

24) Huang Z, Zhang S. Confirmation of amphetamine, methamphetamine, MDA and MDMA in urine samples using disk solid-phase extraction and gas chromatography-mass spectrometry after immunoassay screening. J Chromatogr B Analyt Technol Biomed Life Sci. 2003;792:241-247.

25) Matsuura K, Ohmori T, Nakamura M, et al. A simple and rapid determination of valproic acid in human plasma using a non-porous silica column and liquid chromatography with tandem mass spectrometric detection. Biomed Chromatogr. 2008;22:387-393.

26) Shafaei A, Halim NHA, Zakaria N, et al. Analysis of free amino acids in different extracts of orthosiphon stamineus leaves by high-performance liquid chromatography combined with solid-phase extraction. Pharmacogn Mag. 2017;13:385-391.

27) Velizarova R, Gelisse P, Pageaux GP, et al. Valproate treatment after liver transplant in a patient with LennoxGastaut syndrome. Seizure. 2011;20:500-501.

28) Schulz M, Schmoldt A. Therapeutic and toxic blood concentrations of more than 800 drugs and other xenobiotics. Pharmazie. 2003;58:447-474.

29) Koyama T, Arakawa Y, Shibata M, et al. Effect of barbiturate on central pain: difference between intravenous administration and oral administration. Clin J Pain. 1998;14:86-88.

30) Winek CL, Wahba WW, Winek CL Jr, et al. Drug and chemical blood-level data 2001. Forensic Sci Int. 2001;122:107-123.

31) Huynh F, Mabasa VH, Ensom MH. A critical review: does thiopental continuous infusion warrant therapeutic drug monitoring in the critical care population? Ther Drug Monit. 2009;31:153-169.

32) Viswanathan CT, Bansal S, Booth B, et al. Quantitative bioanalytical methods validation and implementation: best practices for chromatographic and ligand binding assays. Pharm Res. 2007;24:1962-1973.

33) Scientific Working Group for Forensic Toxicology. Scientific Working Group for Forensic Toxicology (SWGTOX) standard practices for method validation in forensic toxicology. J Anal Toxicol. 2013;37:452-474.

[Received January 4, 2018 : Accepted January 16, 2018] 